\title{
Mild Permanent Chronic Thyroid Hormones Insufficiency Induces Cognitive Dysfunction in the Adult Male and Female Rats
}

\author{
Mahdieh Taheri ${ }^{1}$, Tahereh Haghpanah², Gholam Hossein Meftahi ${ }^{3}$, Mohsen Abedini Esfahlani², Fatemeh Gloshan ${ }^{1}$, Khadijeh \\ Esmailpour ${ }^{1}$, Iman Znangiabadi ${ }^{2}$, Yaser Masoumi-Ardakani ${ }^{4}$, Fatemeh Nouri ${ }^{1}$, Vahid Sheibani ${ }^{1}$, Mohammad Reza Afarinesh ${ }^{1}$ * \\ ${ }^{1}$ Kerman Cognitive Research Center and Kerman Neuroscience Research Center, Institute of Neuropharmacology, Kerman University of Medical Sciences, \\ Kerman, Iran. \\ ${ }^{2}$ Department of anatomy, Afzalipour Faculty of Medicine, Kerman University of Medical Sciences, Kerman, Iran. \\ ${ }^{3}$ Neuroscience Research Center, Baqiyatallah University of Medical Sciences, Tehran, Iran. \\ ${ }^{4}$ Physiology Research Center, Institute of Neuropharmacology, Kerman University of Medical Sciences, Kerman, Iran.
}

\section{ARTICLE INFO \\ Article history: \\ Received on: 04/03/2018 \\ Accepted on: 30/04/2018 \\ Available online: 30/07/2018}

\section{Key words:}

Neonatal hypothyroidism,

Spatial learning, Morris

Water Maze, Novel object

recognition, Rats.

\begin{tabular}{l} 
ABSTRACT \\
\hline Objectives: Hypothyroidism is believed to result in irreversible neurological and cognitive impairments. The aim \\
of this study was to examine cognitive functions of male and female rat offspring exposed to 6-propyl-2-thiouracil \\
(PTU) following levothyroxine-therapy. Materials and Methods: Wistar rats were used for the experiment. To induce \\
chronic mild neonatal hypothyroidism in rat offspring, PTU $(1.5,3$, and $6 \mathrm{ppm})$ was added to drinking water of the \\
rat offspring from postnatal day 1 to week 12 . In the separated group, levothyroxine $(50 \mathrm{mg} / \mathrm{kg}$. SC) was injected in \\
the Hypo $6 \mathrm{ppm}$. Morris water maze (MWM) and novel object recognition (NOR) tests were performed at weeks 10 \\
and 12 respectively. Results: In both male and female rats, there was an increase $(\mathrm{P}<0.05)$ in neonatal hypothyroid \\
rats' escape latency and traveled distance to find the hidden platform in MWM compared to those of control. Retrieval \\
memory was impaired in the MWM and the NOR tests. Levothyroxine-therapy resulted in a non-significant difference \\
in the traveled distance and latency delay and retrieval memory of the hypo 6 ppm group compared to controls $(\mathrm{P}$ \\
$>0.05)$. Conclusions: Cognitive impairments following neonatal mild hypothyroidism can disturb hippocampus- \\
dependent learning and memory in both male and female rats. Treatment with levothyroxine induces an improvement \\
in disorders of both male and female genders.
\end{tabular}

\section{INTRODUCTION}

Hypothyroidism is an insufficiency for production or activation of thyroid hormones (TH). Subsequent to Gull's premier in the description of hypothyroidism disease in 1874; the term "myxedema" was coined for this syndrome and had been the predominant term for several years. During the 1900s, it was believed that many patients did not present the sign of disease. Today, it is known that clinical conditions resulting from $\mathrm{TH}$ deficiency mainly depend on intensity, timing, and duration of the deficiency; in addition, they basically affect all tissues to a

\footnotetext{
${ }^{*}$ Corresponding Author

Mohammad Reza Afarinesh, Kerman Cognitive Research Center and Kerman Neuroscience Research Center, Institute of Neuropharmacology, Kerman University of Medical Sciences, Kerman, Iran. E-mail: reza.afarinesh@gmail.com,r.afarinesh@kmu.ac.ir
}

lower or greater extent (Setian, 2007). Nevertheless, congenital hypothyroidism induces more damaging consequences from morphological, biochemical, anatomical and functional changes in developing brain (Rastogi and LaFranchi, 2010; Afarinesh and Behzadi, 2017; Afarinesh and Behzadi, 2018).

Thyroid hormones have an important role in normal development and functions of hippocampus since it is a necessary substrate for some forms of learning and memory. Congenital and neonatal hypothyroidism can cause a wide range of effects from different gene expression in the hippocampus (Esaki et al., 2003; Lee et al., 2003; Dong et al., 2005; Navarro et al., 2015) to cognitive disorders such decreased working memory (Akaike et al., 1991), passive avoidance learning (Darbra et al., 2004), spatial learning memory (Tong et al., 2007), and discrimination behaviors (MacNabb et al., 1999). On the other hand, long-term potentiation (LTP) induction, as a functional integrity of synaptic 
communication in the CA1 area of hippocampus, was changed in hypothyroid rats suggesting that a thyroid dysfunction is related to learning deficits according to several studies (Gilbert, 2004; Gilbert and Sui, 2006; Taskin et al., 2011).

Levothyroxine is the standard of care to treat thyroid hormone deficiency including myxedema coma, thyroid tumors, goiter as a generic medication. As a synthetic form of T4, this endogenous hormone is secreted by the thyroid gland to convert to its active metabolite, L-triiodothyronine (T3) (Jonklaas et al., 2014). Previous studies suggest levothyroxine treatment in early pregnancy recovers subclinical hypothyroidism and impaired spatial learning in the offspring (Wang et al., 2012). However, it has been shown that levothyroxine reversed hypothyroidisminduced impairment of hippocampus-dependent cognition in thyroidectomized adult rats (Fu et al., 2014). It should be noted that while many previous studies have shown that hypothyroidism can cause cognitive impairment (Tong and Chen, 2007; van Wijk et al., 2008; Taskin and Artis, 2011), long-term therapeutic effects of levothyroxine on permanent neonatal mild hypothyroidism has yet remained unresolved in both adult male and female offspring. The present study investigates the effect of treatment with levothyroxine on spatial learning and retrieval memory in adult rat offspring exposed to PTU by using MWM test and Novel object recognition (NOR) test.

\section{MATERIALS AND METHODS}

\section{Animals}

Wistar rats $(250 \pm 25)$ were obtained from the Animal House at Kerman Neuroscience Research Center in order to be used in the present study. The animals were housed in the standard 12-hrs light/dark ad libitum free access to water and food. A total number of 126 rats (including 42 pregnant mothers and their 84 pups) were used as the population of the present study. From each pregnant mother, only one male and one female pup were randomly chosen to include two male and female groups of the study. From the population of 84 pups, 56 rats (with equal numbers for male and female) were born from 28 mothers and were subjected to mild and permanent Hypothyroidism. The mentioned sample included the experimental group of 21 female and 21 male rats which were divided into three groups $(n=7)$ for Propylthiouracil (PTU) at doses of 1.5, 3, and 6 ppm (PTU was added to drinking water of the mentioned pups and their mothers from PND 1 to week 12). Moreover, 14 pups ( 7 male/7 female) born from 7 mothers were subjected in the control group (CTR) which had no medical intervention.

For the study of levothyroxine therapy, the remaining number of 28 pups left from the first total population of 84 rats (14 male/14 female) was born from 14 pregnant mothers. The first group included 14 pups (male and female) in which Hypo $6 \mathrm{ppm}$ was induced (as mentioned above) and levothyroxine (50 $\mathrm{mg} / \mathrm{kg}$, SC Iran Hormone Co.) was injected for two weeks (10 to 12). In the normal group (including 14 pups), the only saline was administrated $(0.3 \mathrm{ml})$ in the respective volume injection.

For hypothyroidism confirmation, blood samplings were obtained from the tail of the rats on the week 10 to free thyroxine hormone (T4) determination. Samples were centrifuged at 3000 rpm for $15 \mathrm{~min}$, and the plasma was stored in a microtube. T4 concentrations were determined using the T4 kit (DiaPlus Inc Co., Canada). All experimental procedures were done in accordance with guidelines of Kerman University of Medical Sciences and the Kerman Neuroscience Research Committee Ethics, EC/ KNRC/95-12.

\section{Morris water maze (MWM)}

\section{Apparatus}

The MWM test was used to evaluate spatial learning. The MWM consisted of a black circular pool (diameter: $150 \mathrm{~cm}$ and height: $60 \mathrm{~cm}$ ), filled to a depth of $30 \mathrm{~cm}$. The water temperature was controlled automatically at $22 \pm 1{ }^{\circ} \mathrm{C}$. After dividing the maze environment into four equal quadrants, a hidden circular Plexiglas platform (10 $\mathrm{cm}$ in diameter) was located at the center of the southwest quadrant. The platform was submerged $1.5 \mathrm{~cm}$ beneath the surface of the water. Fixed extra-maze visual cues i.e., computer, MWM hardware, and posters were present at various locations around the maze. Using a camera above the center of the maze, the animal motion was recorded and saved in the computer. Tracking system available by a commercial software (Noldus, Netherlands; version: $6 \mathrm{XT}$ ) was opted in order to measure the distance moved, escape latency and swimming speed to find the hidden platform (Saberi Moghadam et al., 2013; Sepehri et al., 2014).

\section{Behavioral procedure}

1- Habituation: Each rat was placed individually on the platform for $20 \mathrm{sec}$ and swam in the pool environment for $180 \mathrm{sec}$ on the first day.

2- Training trial: In orientation training, rats were released from four different positions of the maze and were allowed to find the platform in three blocks. Each block contained 4 trials and maximum duration of each trial was $90 \mathrm{sec}$ with an inter-trial interval of 60 seconds. If the rat failed to find the hidden platform, they were placed on the platform for $10 \mathrm{sec}$ (reinforcement). In each trial, the rats were gently placed into the MWM at the middle of the circular edge in a randomly selected quadrant, and their nose was pointed toward the wall. All the experiment was performed routinely between 10:00 AM and 17:00 PM. The distance moved (the pathway required for the rat to find the platform) and escape latency (the time required for the rat to find the platform) was recorded in each trial. The total average of the three blocks for two mentioned parameters during the training phase was also recorded by a video camera.

3 - In the probe test, the platform was removed from the pool and each rat was placed into the pool from the opposite quadrant. This phase consisted of $60 \mathrm{sec}$ free swim period without a platform. The time spent in the trigger zone to find the hidden platform and the swimming speed of the rats was also recorded by a video camera (Saberi Moghadam and Sepehri, 2013; Sepehri and Parsania, 2014).

\section{Novel object recognition test}

NOR test was performed within two days. On the first day, each animal was placed in an opaque plastic chamber $(60$ $\times 60 \times 60 \mathrm{~cm})$ for 10 minutes. During the familiarization phase (encoding) on the second day, two identically familiar objects 
were placed at a distance of $4 \mathrm{~cm}$ from the two walls in the box, and the rat was allowed to explore the box for 5 minutes. After a prescribed delay interval of $45 \mathrm{~min}$, during test phase (retrieval), a new object was replaced instead of one of the objects and the rat was returned to the box; then the animal was allowed to explore the objects for 5 minutes. All of the events were recorded with a video camera that was set on the wall directly above the chamber to offline analysis. The percentage of time that a rat spent exploring the novel object during encoding was calculated as the preference index. After each experiment, the box was cleaned with 70\% alcohol (Chen et al., 2015).

\section{Statistical analysis}

SPSS software version (16.0) was used to analyze the data and Prism software (version 6) was utilized for Graphical figures painting. Repeated measures analysis of variance (ANOVA) and one- or two-way ANOVA followed by Bonferroni Post hoc tests were used to analyze the quantitative differences of parameters. Data were expressed as mean \pm SEM. P-value $<0.05$ was considered statistically significant.

\section{RESULTS}

\section{Hypothyroidism confirmation}

Two way ANOVA revealed the main significant effect for the treatment $\left(\mathrm{F}_{4,46}=15.59, \mathrm{P}=0.001\right)$, and interaction group $\times$ gender $\left(\mathrm{F}_{4,46}=4.6, \mathrm{P}=0.001\right)$ but not for gender $\left(\mathrm{F}_{1,46}=3.6, \mathrm{P}=\right.$ 0.06). The Hypo 6 ppm group showed a decrease in the plasma T4 concentration in both male and female subjects (Fig. 1; $\mathrm{P}<0.001$ and $\mathrm{P}<0.01$, respectively). In a levothyroxine-treated group, compared to the control group, the plasma $\mathrm{T} 4$ concentration showed no significant difference in both male and female rats. The comparison between the levothyroxine-treated and the Hypo 6 group showed that the plasma T4 concentration increased in both groups.

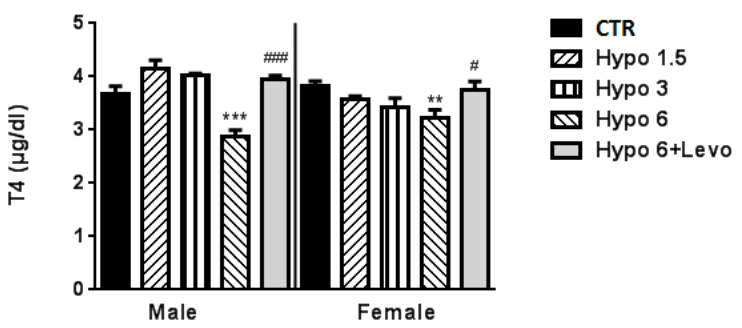

Fig. 1: Plasma T4 concentration level. The effect of PTU-exposure $(1.5,3$, and $6 \mathrm{ppm}$ ) and levothyroxine therapy (Hypo $6 \mathrm{ppm}+$ Levo) on the plasma T4 concentration level of the neonatal hypothyroidism in male and female offspring. Data are expressed as mean \pm SEM. P-values $<0.05$ was considered statistically significant. $* *=\mathrm{P}<0.01, * * *=\mathrm{P}<0.001$ neonatal drug exposure

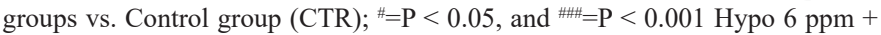
Levo group vs. Hypo 6 ppm group.

\section{MWM: the phase training}

Two-way ANOVA of total distance moved by rats to find the hidden platform in MWM showed a significant main effect of PTU exposure $\left(\mathrm{F}_{4,549}=9.8, \mathrm{P}=0.000\right)$, and gender $\left(\mathrm{F}_{1,549}\right.$ $=5.1, \mathrm{P}=0.01)$ but no effects on treatment $\times$ gender interactions $\left(\mathrm{F}_{4,549}=0.5, \mathrm{P}=0.71\right)$ were recorded. Both male and female hypothyroid subjects in Hypo 3 and 6 ppm groups showed a remarkable increase in their total distance moved to find the hidden platform in MWM compared to their homolog groups ( $\mathrm{P}$ $<0.05$; Fig. 2A). In both male and female rats, treatment with levothyroxine made a significant decrease in the distance moved to find the hidden platform compared to the Hypo 6 group. There was no significant difference between the levothyroxine group and the control group.

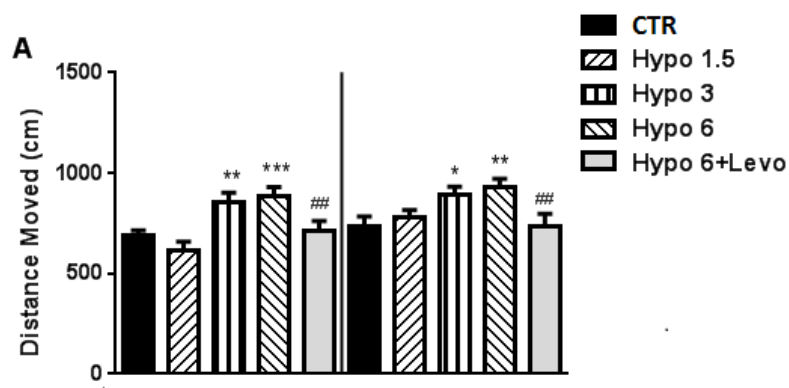

B

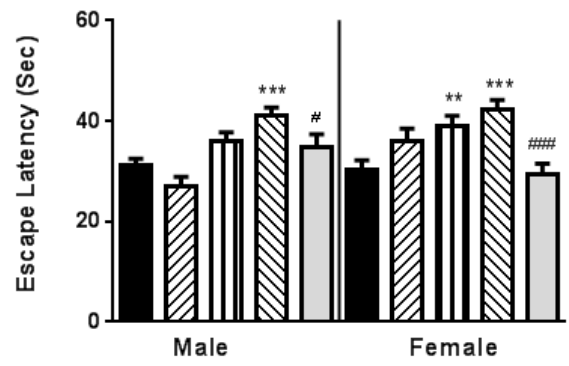

Fig. 2: The effect of PTU-exposure $(1.5,3$, and $6 \mathrm{ppm})$ and levothyroxine therapy (Hypo 6 ppm + Levo) on the total distance moved (A) and total escape latency (B) of the neonatal hypothyroidism rats to find the hidden platform during the three blocks of training in the Morris Water Maze of male and female offspring. Data are expressed as mean \pm SEM. P-values $<0.05$ was considered statistically significant. $*=\mathrm{P}<0.05, * *=\mathrm{P}<0.01, * * *=\mathrm{P}<0.001$ neonatal drug exposure groups vs. Control group (CTR); ${ }^{\#}=\mathrm{P}<0.05,{ }^{\#}=\mathrm{P}<0.01$, and ${ }^{\# \#}=\mathrm{P}<$ 0.001 Hypo 6 ppm + Levo group vs. Hypo 6 ppm group.

Also, total escape latency of rats to find the hidden platform in MWM showed a significant main effect for PTU exposure $\left(\mathrm{F}_{4,518}=9.5, \mathrm{P}=0.000\right)$, and gender $\left(\mathrm{F}_{1,518}=3.5, \mathrm{P}\right.$ $=0.05)$ but the treatment $\times$ gender interactions failed to reach a significant effect $\left(\mathrm{F}_{4,518}=2.2, \mathrm{P}=0.06\right)$. Male Hypothyroid subjects in Hypo $6 \mathrm{ppm}$ group and also female hypothyroid subjects in Hypo 3 and 6 ppm groups showed a significant increase in their total escape latency to find the hidden platform in MWM compared to their homolog CTR groups $(\mathrm{P}<0.05$; Fig. 2B). Moreover, in both male and female rats, treatment with levothyroxine affected on decreasing escape latency to find the hidden platform compared to the Hypo 6 group. Considering this, no significant difference was observed between levothyroxine treated and control group.

Male: A repeated measurement of ANOVA showed that the distance moved and escape latency of male rats to find the hidden platform in MWM was significantly altered during the three blocks of learning phase in all control and hypothyroid groups $\left[\left(\mathrm{F}_{2,506}=69.7, \mathrm{P}=0.001\right)\right.$ and $\left(\mathrm{F}_{2,508}=\right.$ $46.4, \mathrm{P}=0.001)$, respectively]. Also, Interaction of Block $\times$ 
treatment revealed a significant effect for these factors $\left[\left(\mathrm{F}_{8,506}\right.\right.$ $=3.9, \mathrm{P}=0.001)$ and $\left(\mathrm{F}_{8,508}=2.4, \mathrm{P}=0.015\right)$, respectively]. Bonferroni Post hoc test showed both the distance moved and the escape latency to find the hidden platform in Hypo 3 and $6 \mathrm{ppm}$ groups increased significantly in block III $(\mathrm{P}<0.05)$, as compared to the control (Figs. 3A, 3B). Treatment with levothyroxine can significantly reduce the distance moved to find the hidden platform compared to the Hypo 6 group in block I; with regards to this, no meaningful difference between the two groups of levothyroxine-treated and control was observed. Moreover, treatment with levothyroxine significantly reduced escape latency to find the hidden platform compared to Hypo 6 group in block III. The comparison of these parameters between levothyroxine-treated and control group in blocks I, II and III showed no meaningful statistical difference.

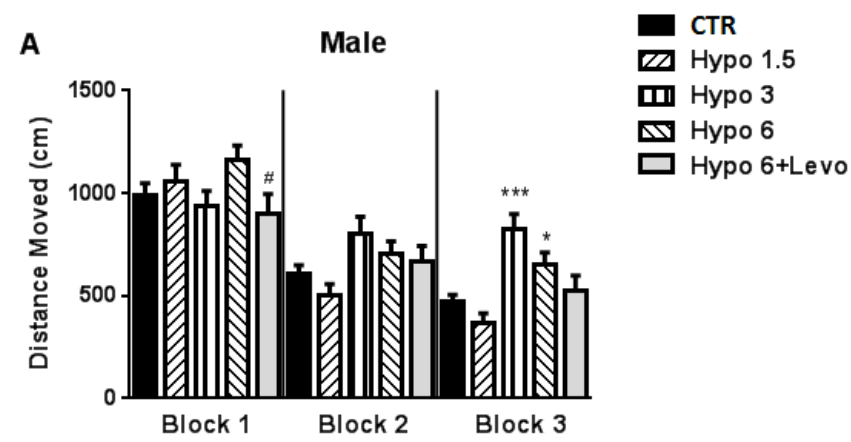

B

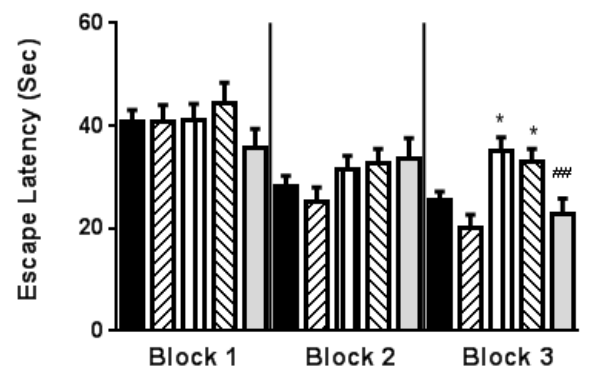

Fig. 3: The effect of PTU-exposure $(1.5,3$, and $6 \mathrm{ppm})$ and levothyroxine therapy (Hypo $6 \mathrm{ppm}+$ Levo) on the distance moved (A) and the escape latency (B) of the male neonatal hypothyroid rats to find the hidden platform during the three blocks of training in Morris Water Maze. Data are expressed as mean \pm SEM. P-values $<0.05$ was considered statistically significant. $* *=\mathrm{P}<0.01$, $* * *=\mathrm{P}<0.001$ neonatal drug exposure groups vs. Control group (CTR); ${ }^{\#}=\mathrm{P}<$ 0.05 and ${ }^{\#}=\mathrm{P}<0.01$, Hypo $6 \mathrm{ppm}+$ Levo group vs. Hypo 6 ppm group.

Female: A repeated measurement of ANOVA showed that the distance moved and escape latency of female rats to find the hidden platform in MWM was significantly changed during the three blocks of learning phase in all control and hypothyroid groups $\left[\left(\mathrm{F}_{2,404}=65, \mathrm{P}=0.001\right)\right.$ and $\left(\mathrm{F}_{2,404}=44.8, \mathrm{P}=0.001\right)$, respectively]. Also, Interaction of block $\times$ treatment was significant for these factors $\left[\left(\mathrm{F}_{8,404}=1.03, \mathrm{P}=0.015\right)\right.$ and $\left(\mathrm{F}_{8,404}=1.03, \mathrm{P}=\right.$ 0.18), respectively]. Bonferroni Post hoc test showed that both the distance moved and the escape latency to find the hidden platform of Hypo 3 and $6 \mathrm{ppm}$ increased significantly compared to the control in block III $(\mathrm{P}<0.01$ and $\mathrm{P}<0.001$, respectively (Figs. 4A, 4B). Treatment with levothyroxine significantly reduced the distance moved to find the hidden platform and escape latency compared to Hypo 6 group in block III; regarding this, no significant difference was observed between levothyroxine-treated group and control group in block I, II and III.
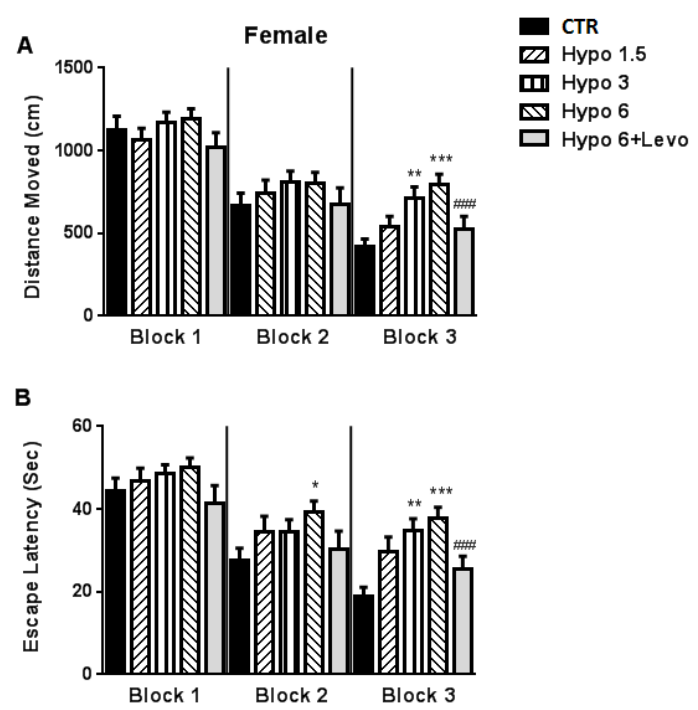

Fig. 4: The effect of PTU-exposure (1.5, 3, and $6 \mathrm{ppm})$ and levothyroxine therapy (Hypo $6 \mathrm{ppm}+$ Levo) on the distance moved (A) and the escape latency (B) of the female neonatal hypothyroid rats to find the hidden platform during the three blocks of training in Morris Water Maze. Data are expressed as mean \pm SEM. P-values $<0.05$ was considered statistically significant. $* *=\mathrm{P}<0.01$, $* * *=\mathrm{P}<0.001$ neonatal drug exposure groups vs. Control group (CTR); ${ }^{\# \#=\mathrm{P}<}$ 0.001, Hypo 6 ppm + Levo group vs. Hypo 6 ppm group.

\section{MWM: the probe test}

Two-way ANOVA of the time spent in trigger zone to find the hidden platform in MWM revealed a significant main effect for PTU exposure $\left(\mathrm{F}_{4,121}=4.9, \mathrm{P}=0.002\right)$, but not for gender $\left(\mathrm{F}_{1,121}=0.46, \mathrm{P}=0.51\right)$, and treatment $\times$ gender interactions $\left(\mathrm{F}_{4}\right.$ $\left.{ }_{121}=0.28, \mathrm{P}=0.88\right)$. A significant decrease of the time spent in trigger zone was observed in Hypo 6 ppm group compared to control $(\mathrm{P}<0.05$; Fig. $5 \mathrm{~A})$ in the probe-testing day. In both male and female rats, the percentage of time spent in the trigger zone during probe testing was shown to have no significant difference between levothyroxine-treated group compared to the control group. Treatment with levothyroxine improves the time spent in the trigger zone during probe testing compared to the Hypo 6 group.

Also, data of the swimming speed of rats to find the hidden platform in MWM did not show a significant main effect for PTU exposure $\left(\mathrm{F}_{4,125}=3.6, \mathrm{P}=0.07\right)$, gender $\left(\mathrm{F}_{1,125}=0.14, \mathrm{P}=\right.$ $0.71)$, and treatment $\times$ gender interactions $\left(\mathrm{F}_{4,125}=1.39, \mathrm{P}=0.24\right)$ (Fig. 5B).

\section{NOR test}

Two-way ANOVA of the preference index to determine new object NOR test revealed a significant main effect for PTU exposure $\left(\mathrm{F}_{4,159}=23.8, \mathrm{P}=0.001\right)$, but not for gender $\left(\mathrm{F}_{1,159}=0.01, \mathrm{P}\right.$ $=0.94)$ and treatment $\times$ gender interactions $\left(\mathrm{F}_{4,159}=0.47, \mathrm{P}=0.75\right)$. A significant decrease of the preference index was observed in all the hypothyroid groups $(1.5,3$, and $6 \mathrm{ppm})$ compared to control in both male and female subjects $(\mathrm{P}<0.05$; Fig. 6$)$. In both male and female rats, new object determination in the levothyroxine-treated 
group had no meaningful difference compared to those of control; treatment with levothyroxine improves new object determination compared to Hypo 6 group.
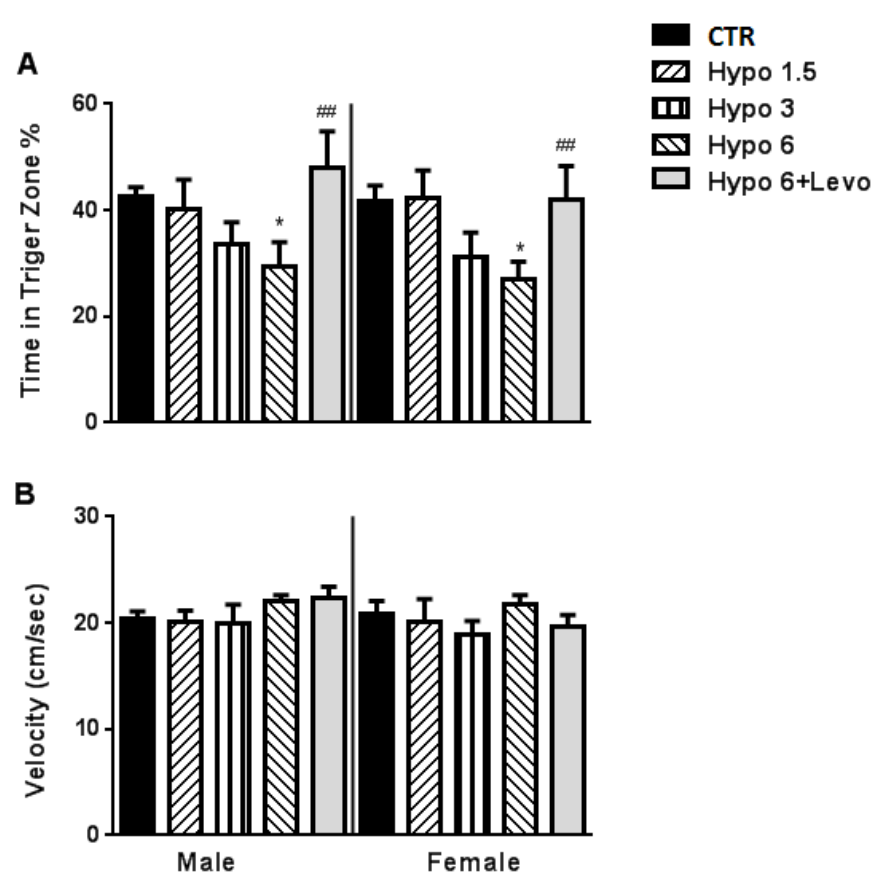

Fig. 5: The effect of PTU-exposure (1.5, 3, and 6 ppm) on the time spent in the trigger zone (A) and the swimming velocity (B) of male and female neonatal hypothyroid rats in the probe test in Morris Water Maze. Data are expressed as mean \pm SEM. P-values $<0.05$ was considered statistically significant. ${ }^{*}=\mathrm{P}<$ 0.05 , neonatal drug exposure groups vs. Control group (CTR); ${ }^{\#=}=\mathrm{P}<0.01$, Hypo $6 \mathrm{ppm}+$ Levo group vs. Hypo 6 ppm group.

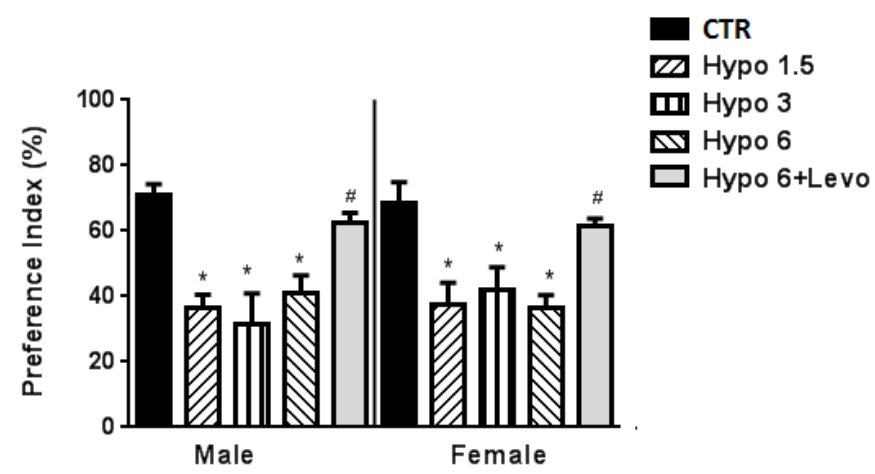

Fig. 6: The effect of PTU-exposure (1.5,3, and $6 \mathrm{ppm})$ and levothyroxine therapy (Hypo $6 \mathrm{ppm}+$ Levo) on the percentage of preference index of male and female neonatal hypothyroid rats in the novel object recognition test. Data are expressed as mean \pm SEM. P-values $<0.05$ was considered statistically significant. ${ }^{*}=\mathrm{P}<$ 0.05 , neonatal drug exposure groups vs. Control group (CTR); $\#=\mathrm{P}<0.05$, Hypo 6 ppm + Levo group vs. Hypo 6 ppm group.

In parallel to previous studies (Sui and Gilbert, 2003), our study confirmed that plasma T4 concentration level in the rat offspring treated with PTU (6 ppm) was significantly lower than in the corresponding control groups. Treatment with levothyroxine can increase the T4 concentration level in blood serum of male and female hypothyroid rats.
The main finding of the present study showed that mild chronic neonatal hypothyroidism impairs spatial and non-spatial learning and retrieval memory of rats; moreover, treatment with levothyroxine improves impairment in the cognitive function of spatial memory and learning as well as new object determination. Mild, permanent, and neonatal hypothyroidism can impair spatial learning because the distance moved is decreased and the escape latency is increased to find the hidden platform in the MWM on the training phase in both the male and female rats. In the block I, there is no significant difference for PTU exposed animals' performance compared to those of controls, this suggests that the impaired learning is not caused by non-specific effects such as disrupted motor performance. Our results are consistent with other previous studies which show that congenital hypothyroidism impairs spatial learning and memory related to hippocampus integrity (Akaike and Kato, 1991; Tong and Chen, 2007; Hosseini et al., 2010; Shafiee et al., 2017). However, male and female neonatal hypothyroid groups of the present study are similar to congenital hypothyroid rats (Shafiee and Vafaei, 2017) which exhibit an identical pattern learning similar to the control group, suggesting that spatial learning is not impaired in neonatal and congenital hypothyroid rats completely. Moreover, it has been reported that chronic exposure to iodide-poor diet for more than two months affects spatial memory in a negative manner, but in perinatal hypothyroidism, spatial memory is impaired in female rats only (van Wijk and Rijntjes, 2008).

Moreover, our results demonstrate that retrieval memory of neonatal hypothyroid rats can be impaired in MWM as there is a decrease of the time spent in trigger zone to find the hidden platform in probe test as well as the NOR test; additionally, a decreased percentage of preference index is evidenced in both male and female subjects. These tests are the standard test of cognition in spatial and non-spatial memory in the rodents which depend on the integration of the rodent hippocampus to spatial and object memory (Barzegar et al., 2015; Cohen and Stackman, 2015; Xing et al., 2016). The present study is in contrast to recent studies claiming that thyroid peroxidase inhibitor methimazole-exposure of pregnant rat from gestational day 9 up to delivery, increases the pups' novelty-directed exploratory behaviors at PND 35-40 (Melancia et al., 2017). It shall be noted that different types of hypothyroidism induction and age of subject may exert different effects on various forms of learning and memory. As mentioned above, the MWM and NOR tasks rely on the hippocampus functions (van Wijk and Rijntjes, 2008; Cohen and Stackman, 2015). Hypothyroidism can reduce the volume of the hippocampus (Hasegawa et al., 2010); it additionally decreases the density of neurons in all pyramidal cell layer of the hippocampus (Cattani et $a l ., 2013$ ), and also synaptic plasticity in the hippocampus (Taskin and Artis, 2011). Hypothyroidism can lead to alterations in proteins such as brain-derived neurotrophic factor protein (Shafiee and Vafaei, 2017), calcium and glutamate uptake and transporters (Dong and Yin, 2005), inasmuch as glutamate homeostasis (Cattani and Goulart, 2013), ERK activation (Sui et al., 2005), and also a decrease in C-fos and C-jun expression (Dong and Yin, 2005) in the hippocampus. Therefore, behavioral deficits described in male and female neonatal hypothyroid rats of the present study can be a result of impairment in their hippocampus functions.

However, the velocity parameter is evaluated in the 
probe test to show that an improved or impaired learning is not influenced by motor activities in the MWM test. In contrast with our finding, a study in which permanent hypothyroid and neonatal hypothyroid was induced through the use of a diet without iodine, documents that motor activities of rats in open field test would damage (van Wijk and Rijntjes, 2008). In contrast, temporary hypothyroidism in the neonatal period coursed hyperactivity in rats (Akaike and Kato, 1991).

Thyroid hormones are a necessity for normal function of the hippocampus. It has been shown that treatment with levothyroxine significantly affects spatial memory and learning in normal and hypothyroid rats. Using their genomic and nongenomic receptors, thyroid hormones can regulate biological cell activities by gene transcription. It is also illustrated that thyroxine regulates hundreds of genes, e.g. those related to central nervous system memory. Consumption of L-T4 significantly increases the level of proteins related to memory, such as choline acetyltransferase, superoxide dismutase, nerve growth factor, and Glutathione peroxidase in the hippocampus (Smith et al., 2002; Fu and Zhou, 2014). With regards to the facts that the processes of memory stabilization and restoring need synthesis of de novo protein and thyroid hormones adjust gene transcription related to memory, it is believed that levothyroxine injection to hypothyroid rats can increase protein synthesis related to memory and learning which results in a progress in memory and learning. Yet, the relevant molecular mechanisms on memory and learning improvement which happen as a result of levothyroxine therapy in hypothyroid rats are not distinct and therefore it proposes future studies.

\section{CONCLUSION}

In conclusion, we demonstrated that the permanent administration of mild PTU to rats from PND 1 to adult period disturbs spatial and non-spatial learning and memory in the MWM and the NOR tests. No gender-dependent effects were found in learning and memory performance, suggesting a similar impairment in cognitive functions in both genders following neonatal thyroid hormone deficiency. According to our findings, treatment with levothyroxine can increase the density of thyroxin in hypothyroid male and female rats to the control level. This change in the level of thyroid hormones can cause impairment in cognitive functions of spatial memory and learning as well as the ability to distinguish a new object.

\section{ACKNOWLEDGMENTS}

This study is supported by Kerman Neuroscience Research Center entitled to EC/KNRC/95-12. The authors truly appreciate the cooperation of the staff at this center.

\section{CONFLICT OF INTEREST}

The authors declare no conflict of interest.

\section{REFERENCES}

Afarinesh MR, Behzadi G. The pattern of thalamocortical and brain stem projections to the vibrissae-related sensory and motor cortices in de-whiskered congenital hypothyroid rats. Metab Brain Dis, 2017; 32:1223-1235.

Afarinesh MR, Behzadi G. The effects of de-whiskering and congenital hypothyroidism on the development of nitrergic neurons in rat primary somatosensory and motor cortices. Cell J, 2018; 20:157-167.

Akaike M, Kato N, Ohno H, Kobayashi T. Hyperactivity and spatial maze learning impairment of adult rats with temporary neonatal hypothyroidism. Neurotoxicol Teratol, 1991; 13:317-322.

Barzegar M, Sajjadi FS, Talaei SA, Hamidi G, Salami M. Prenatal exposure to noise stress: anxiety, impaired spatial memory, and deteriorated hippocampal plasticity in postnatal life. Hippocampus, 2015; 25:187-196.

Cattani D, Goulart PB, Cavalli VL, Winkelmann-Duarte E, Dos Santos AQ, Pierozan P, de Souza DF, Woehl VM, Fernandes MC, Silva FR, Goncalves CA, Pessoa-Pureur R, Zamoner A. Congenital hypothyroidism alters the oxidative status, enzyme activities and morphological parameters in the hippocampus of developing rats. Mol Cell Endocrinol, 2013; 375:1426.

Chen HH, Chiang YC, Yuan ZF, Kuo CC, Lai MD, Hung TW, Ho IK, Chen ST. Buprenorphine, methadone, and morphine treatment during pregnancy: behavioral effects on the offspring in rats. Neuropsychiatr Dis Treat, 2015; 11:609-618.

Cohen SJ, Stackman RW, Jr. Assessing rodent hippocampal involvement in the novel object recognition task. A review. Behav Brain Res, 2015; 285:105-117.

Darbra S, Balada F, Marti-Carbonell MA, Garau A. Perinatal hypothyroidism effects on step-through passive avoidance task in rats. Physiol Behav, 2004; 82:497-501.

Dong J, Yin H, Liu W, Wang P, Jiang Y, Chen J. Congenital iodine deficiency and hypothyroidism impair LTP and decrease C-fos and C-jun expression in rat hippocampus. Neurotoxicology, 2005; 26:417-426.

Esaki T, Suzuki H, Cook M, Shimoji K, Cheng SY, Sokoloff L, Nunez J. Functional activation of cerebral metabolism in mice with mutated thyroid hormone nuclear receptors. Endocrinology, 2003; 144:4117-4122.

$\mathrm{Fu} \mathrm{A}$, Zhou $\mathrm{R}, \mathrm{Xu} \mathrm{X}$. The synthetic thyroid hormone, levothyroxine, protects cholinergic neurons in the hippocampus of naturally aged mice. Neural Regen Res, 2014; 9:864-871.

Gilbert ME. Alterations in synaptic transmission and plasticity in area CA1 of adult hippocampus following developmental hypothyroidism. Brain Res Dev Brain Res, 2004; 148:11-18.

Gilbert ME, Sui L. Dose-dependent reductions in spatial learning and synaptic function in the dentate gyrus of adult rats following developmental thyroid hormone insufficiency. Brain Res, 2006; 1069:1022.

Hasegawa M, Kida I, Wada H. A volumetric analysis of the brain and hippocampus of rats rendered perinatal hypothyroid. Neurosci Lett, 2010; 479:240-244.

Hosseini M, Dastghaib SS, Rafatpanah H, Hadjzadeh MA, Nahrevanian H, Farrokhi I. Nitric oxide contributes to learning and memory deficits observed in hypothyroid rats during neonatal and juvenile growth. Clinics (Sao Paulo), 2010; 65:1175-1181.

Jonklaas J, Bianco AC, Bauer AJ, Burman KD, Cappola AR, Celi FS, Cooper DS, Kim BW, Peeters RP, Rosenthal MS, Sawka AM. Guidelines for the treatment of hypothyroidism: prepared by the american thyroid association task force on thyroid hormone replacement. Thyroid, 2014; 24:1670-1751.

Lee PR, Brady D, Koenig JI. Thyroid hormone regulation of $\mathrm{N}$-methyl-D-aspartic acid receptor subunit mRNA expression in adult brain. J Neuroendocrinol, 2003; 15:87-92.

MacNabb C, O’Hare E, Cleary J, Georgopoulos AP. Congenital hypothyroidism impairs response alternation discrimination behavior. Brain Res, 1999; 847:231-239.

Melancia F, Servadio M, Schiavi S, Campolongo P, GiustiPaiva A, Trezza V. Testing the correlation between experimentally-induced hypothyroidism during pregnancy and autistic-like symptoms in the rat offspring. Behav Brain Res, 2017; 321:113-122.

Navarro D, Alvarado M, Navarrete F, Giner M, Obregon MJ, Manzanares J, Berbel P. Gestational and early postnatal hypothyroidism alters VGluT1 and VGAT bouton distribution in the neocortex and 
hippocampus, and behavior in rats. Front Neuroanat, 2015; 9:9.

Rastogi MV, LaFranchi SH. Congenital hypothyroidism. Orphanet J Rare Dis, 2010; 5:17.

Saberi Moghadam A, Sepehri G, Sheibani V, Haghpanah T, Divsalar K, Hajzadeh MA, Afarineshkhaki M. The Effect of Opium Dependency of Parent (s) on Offspring's Spatial Learning \& Memory in Adult Male Rats. Iran J Basic Med Sci, 2013; 16:694-699.

Sepehri G, Parsania S, Hajzadeh MA, Haghpanah T, Sheibani V, Divsalar K, Shekarforoush S, Afarinesh MR. The effects of coadministration of opium and morphine with nicotine during pregnancy on spatial learning and memory of adult male offspring rats. Iran J Basic Med Sci, 2014; 17:694-701.

Setian NS. Hypothyroidism in children: diagnosis and treatment. J Pediatr (Rio J), 2007; 83:S209-216.

Shafiee SM, Vafaei AA, Rashidy-Pour A. Effects of maternal hypothyroidism during pregnancy on learning, memory and hippocampal BDNF in rat pups: Beneficial effects of exercise. Neuroscience, 2017; 329:151-161.

Smith JW, Evans AT, Costall B, Smythe JW. Thyroid hormones, brain function and cognition: a brief review. Neurosci Biobehav Rev, 2002; 26:45-60.

Sui L, Anderson WL, Gilbert ME. Impairment in short-term but enhanced long-term synaptic potentiation and ERK activation in adult hippocampal area CA1 following developmental thyroid hormone insufficiency. Toxicol Sci, 2005; 85:647-656.

Sui L, Gilbert ME. Pre- and postnatal propylthiouracil-induced hypothyroidism impairs synaptic transmission and plasticity in area CA1 of the neonatal rat hippocampus. Endocrinology, 2003; 144:4195-4203.

Taskin E, Artis AS, Bitiktas S, Dolu N, Liman N, Suer C. Experimentally induced hyperthyroidism disrupts hippocampal long-term potentiation in adult rats. Neuroendocrinology, 2011; 94:218-227.

Tong H, Chen GH, Liu RY, Zhou JN. Age-related learning and memory impairments in adult-onset hypothyroidism in Kunming mice. Physiol Behav, 2007; 91:290-298.

van Wijk N, Rijntjes E, van de Heijning BJ. Perinatal and chronic hypothyroidism impair behavioural development in male and female rats. Exp Physiol, 2008; 93:1199-1209.

Wang S, Teng W, Gao Y, Fan C, Zhang H, Shan Z. Early levothyroxine treatment on maternal subclinical hypothyroidism improves spatial learning of offspring in rats. J Neuroendocrinol, 2012; 24:841-848.

Xing Y, Chen W, Wang Y, Jing W, Gao S, Guo D, Xia Y, Yao D. Music exposure improves spatial cognition by enhancing the BDNF level of dorsal hippocampal subregions in the developing rats. Brain Res Bull, $2016 ; 121: 131-137$

\section{How to cite this article:}

Taheri M, Haghpanah T, Meftahi GH, Abedini-Esfahlani M, Gloshan F, Esmailpour K, Znangiabadi I, Masoumi-Ardakani Y, Nouri F, Sheibani V, Afarinesh M. Mild Permanent Chronic Thyroid Hormone Insufficiency Induces Cognitive Dysfunction in the Adult Male and Female Rats. J App Pharm Sci, 2018; 8(07): 100-106. 